\title{
Blockage of cisplatin-induced autophagy sensitizes cervical cancer cells to cisplatin
}

\author{
W.M. Lin and Z.G. Li \\ Department of Gynecology, Guangdong General Hospital (Guangdong Academy of \\ Medical Sciences), Guangzhou, China \\ Corresponding author: Z.G. Li \\ E-mail: guangdongzhigang@163.com
}

Genet. Mol. Res. 14 (4): 16905-16912 (2015)

Received July 20, 2015

Accepted September 3, 2015

Published December 14, 2015

DOI http://dx.doi.org/10.4238/2015.December.14.18

ABSTRACT. Development of chemoresistance is a major obstacle that leads to the recurrence and progression of cervical cancer (CC). Autophagy, meaning, "eating of self", has shown paradoxical functions in tumors. In this study, we first investigated the process of autophagy induction by cisplatin in CC cells. Next, we investigated the role of autophagy in cisplatinsensitivity of $\mathrm{CC}$ cells via blockage of cisplatin-induced autophagy. The results demonstrated that cisplatin induces autophagy in CC HeLa cells via upregulating the formation of autophagic vesicle, promoting the conversion of LC-I to LC-II, and increasing the expression of autophagy-related gene 7 (Atg-7). On the other hand, the autophagy inhibitor, 3MA, downregulated cisplatin-induced formation of autophagic vesicles, reduced the conversion of LC-I to LC-II, and decreased Atg-7 expression. Moreover, 3MA reversed the reduction in cellular viability and induction of apoptosis by cisplatin in HeLa cells. Our results imply that autophagy blockage may play a key role in the chemosensitivity of cervical cancers.

Key words: Autophagy; Chemosensitivity; Cervical cancer; Cisplatin 


\section{INTRODUCTION}

Cervical cancer is the third most common cancer among women worldwide, with the fourth highest fatality rates among females (Jemal et al., 2011). In particular, it is still a severe health issue in developing countries, although the incidence of this disease is slowly decreasing in developed countries due to early diagnosis. The Asia Oceania region accounts for more than $50 \%$ of all cases and cervical cancer-related deaths worldwide (Ferlay et al., 2015). Radical treatment of cervical cancer still relies on surgical resection and pelvic node dissection (Verleye et al., 2009). Chemotherapy is one of the most useful strategies in systematic treatment of cervical cancer (Pearcey et al., 2007). Cisplatin-based concurrent chemoradiotherapy (CCRT) is a standard treatment for locally advanced cervical cancer (Lukka et al., 2002; Lanciano et al., 2005; Vale et al., 2008). However, development of chemoresistance poses a major impediment that contributes to tumor recurrence, progression, and certain deaths (Burger et al., 2011).

Autophagy means, "eating of self" and constitutes a basic cellular process of both physiological and pathological importance (Jaeger and Wyss-Coray, 2009; Gibbings et al., 2012). Studies have shown paradoxical functions of autophagy in tumors (Mathew et al., 2007; White and DiPaola, 2009). Autophagy promotes tumor growth during tumor development, and conspires with inflammation (Korkaya and Wicha, 2011; Chen and Guan, 2013). On the other hand, autophagy is also associated with tumor cell death. Tumor-promoting and -suppressive roles of autophagy have been found in the same mouse model of lung cancer (Chen and Guan, 2013). Moreover, autophagy has been shown to be a cell death promoter, and is involved in tumor suppressor mechanisms (Gozuacik and Kimchi, 2004). Therefore, it is not clear whether autophagy induced by chemotherapy contributes to tumor cell death or leads to chemoresistance.

In this study, we investigated autophagy induction by cisplatin in cervical cancer cells, and explored the role of autophagy in cervical cancer cells. Our results imply that autophagy blockage has a chemosensitivity effect on cervical cancers.

\section{MATERIAL AND METHODS}

\section{Cell culture and treatment}

Human cervical cancer HeLa cells were purchased from the American Type Culture Collection (ATCC) (Rockville, MD, USA,) and were cultured in Dulbecco's Modified Eagle's Medium (DMEM) supplemented with 10\% fetal bovine serum (FBS) (Sijiqing, Hangzhou, China), with 50 $\mu \mathrm{g} /$ $\mathrm{mL}$ penicillin and streptomycin (CSPC Pharmaceutical Group Limited, Shijiazhuang, China). Cells were incubated in a humidified chamber at $37^{\circ} \mathrm{C}$ in $5 \% \mathrm{CO}_{2}$. For autophagy induction, HeLa cells (>85\% confluent) were treated with either $100 \mathrm{nM}$ rapamycin (Sigma-Aldrich, St. Louis, MO, USA), $0.2 \mu \mathrm{g} / \mathrm{mL}$ cisplatin (Sigma-Aldrich, St. Louis, MO, USA) or both agents for 12, 24 or $48 \mathrm{~h}$. For autophagy inhibition, HeLa cells were treated with $1 \mathrm{mM} 3$-methyladenine (3MA) for 12, 24, or $48 \mathrm{~h}$.

\section{Quantitative GFP-LC3 and electron microscopy analysis}

The coding sequences of GFP and LC3 were cloned into pcDAN3.1(+) plasmids (Invitrogen, Carlsbad, CA, USA) with Lipofectamine 2000 (Invitrogen, Carlsbad, CA, USA). Quantitative analysis of acid vesicular organelles (AVO) formation was carried out on HeLa cells transfected with the GFP-LC3 plasmid. After transfection for $6 \mathrm{~h}$, cells were subject to rapamycin or cisplatin treatment for 
another $24 \mathrm{~h}$. Images of GFP-positive vesicles were visualized via fluorescence microscopy.

Observation of autophagic vesicles under electron microscopy was performed as described previously (Mizushima et al., 2008). In brief, HeLa cells post-treatments were collected via centrifugation for $5 \mathrm{~min}$ at $4^{\circ} \mathrm{C}$ and $800 \mathrm{rpm}$. Isolated cells were then serially fixed with $4 \%$ paraformaldehyde in phosphate-buffered saline (PBS) overnight at $4^{\circ} \mathrm{C}$. Cells were then incubated with $1 \% \mathrm{OsO}_{4}$ in cacodylate buffer for $1 \mathrm{~h}$ at room temperature. Post-dehydration with ethanol, cell pellets were embedded in Spurr resin for sectioning. Images of autophagic vesicles were observed under a transmission electron microscope (JEM-1230, Jeol, Tokyo, Japan).

\section{Western blot analysis}

Cellular proteins were extracted from HeLa cells post-treatment with a cell lysis reagent (Promega, Madison, WI, USA), and were quantified using the BCA Protein Assay Reagent Kit (Pierce, Rockford, IL, USA) according to the manufacturers protocol. Protein samples were first separated with $10 \%$ gradient SDS-PAGE gel, and were transferred to polyvinylidene fluoride membrane (Millipore, Bedford, MA, USA). The membrane was incubated with primary rabbit polyclonal antibodies against LC3 (Abcam, Cambridge, UK), autoghagy-related gene (Atg 7; Santa Cruz, CA, USA) or $\beta$-actin (Sinobio, Beijing, China), and was then probed with Goat anti-rabbit IgG (Pierce, Rockford, IL, USA). Finally, specific blots were visualized by enhanced chemiluminescence detection systems (Amersham Pharmacia Biotech, Amersham, UK). The blots were quantified by comparison of gray value of LC3 II to LC3 I, or by comparing the gray value of Atg7 to $\beta$-actin.

\section{MTT assay and apoptosis analysis}

Cell viability was determined by MTT assays. HeLa cells were seeded in 96-well plates, and allowed to attach overnight. Afterwards, cells were treated with $1 \mathrm{mM} \mathrm{3MA}$ or (and) with 0.2 $\mu \mathrm{g} / \mathrm{mL}$ cisplatin. After $12,24,36$, or $48 \mathrm{~h}$ of incubation, cell viability was measured. The MTT assay was conducted according to the standard protocol. Absorbance was measured at $570 \mathrm{~nm}$ with a reference wavelength of $750 \mathrm{~nm}$ using a spectrophotometer.

Apoptosis of treated HeLa cells was analyzed with an annexin V-FITC apoptosis detection kit (Abcam, Cambridge, UK). HeLa cells, post-treatment with $1 \mathrm{mM} \mathrm{3MA}$ or (and) with $0.2 \mu \mathrm{g} / \mathrm{mL}$ cisplatin for 24 or $48 \mathrm{~h}$, were collected and suspended in ice-cold $70 \%$ ethanol overnight for fixation. HeLa cells were then stained with propidium iodide or annexin V-FITC after centrifugation and resuspensions. Apoptotic cells were assayed according to manufacturer instructions using a flow cytometer (BD FACScan). Results were expressed as the percentage of apoptotic cells from the total cells.

\section{Statistical analysis}

All statistical evaluations are reported as means \pm SE. Data were analyzed by the Student $t$-test. The criterion for statistical significance was considered as $\mathrm{P}<0.05$.

\section{RESULTS}

\section{Cisplatin induces autophagy in cervical cancer cells}

Autophagy is characterized by the formation of autophagic vesicles, i.e., AVOs in the cy- 
tosol (Paglin et al., 2001). Cytosolic AVOs can be observed under fluorescence microscope with GFP-LC3 labeled autophagosomes. To confirm autophagy induction in cervical cancer HeLa cells, we examined AVOs formation in HeLa cells, which were subject to $0.2 \mu \mathrm{g} / \mathrm{mL}$ cisplatin. As shown in Figure 1, compared to the control group (Figure 1A), there was significantly higher level of green fluorescent protein (GFP)-positive vesicles in the HeLa cells treated with $100 \mathrm{nM}$ rapamycin (autophagy inducer, as positive control) $(P<0.001$; Figure $1 B)$ or with $0.2 \mu \mathrm{g} / \mathrm{mL}$ cisplatin $(P<0.01$; Figure 1C-D).
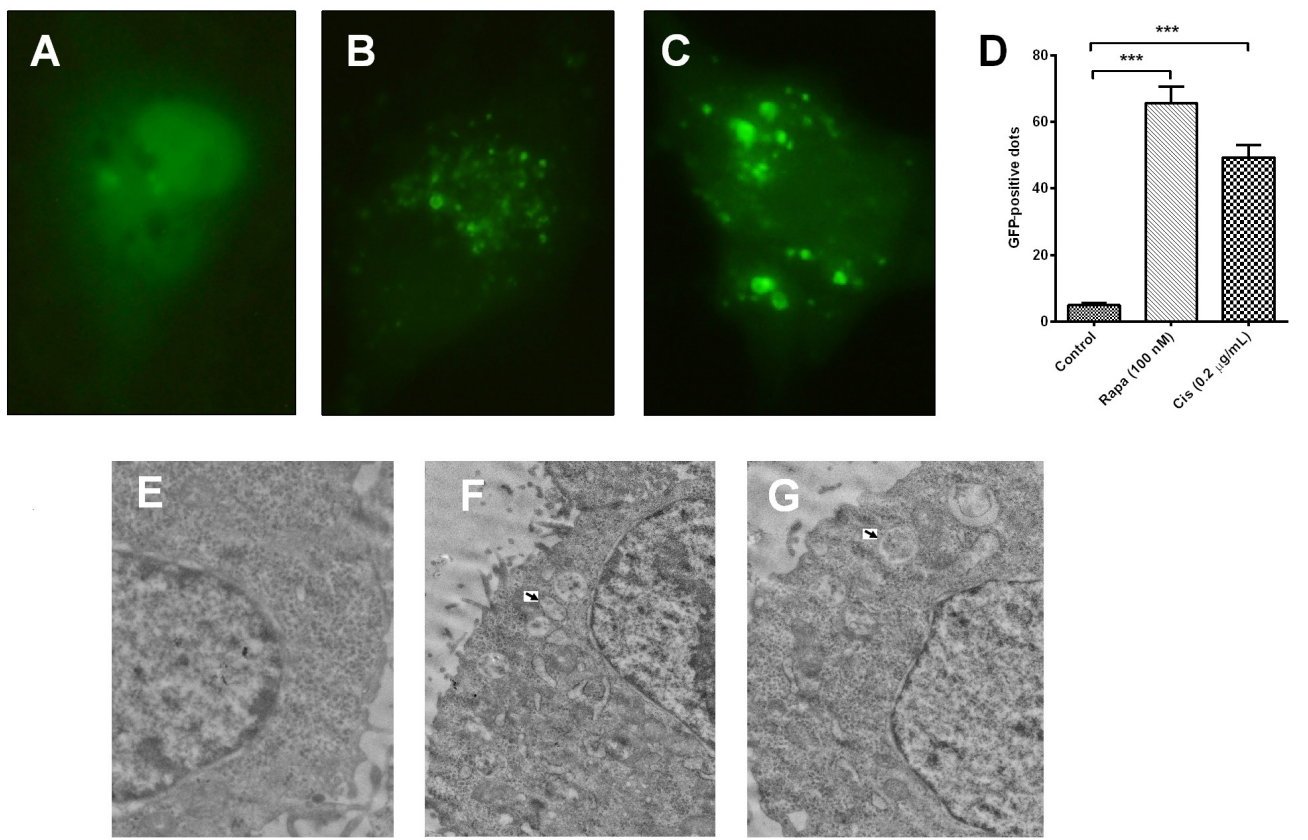

Figure 1. Cisplatin promotes autophagic vesicle formation in HeLa cells (A-C). Autophagic vesicle formation in negative control HeLa cells (A), in HeLa cells treated with $100 \mathrm{nM}(\mathbf{B})$, or $0.2 \mu \mathrm{g} / \mathrm{mL}$ cisplatin (C). Autophagic vesicles are shown as green fluorescence protein (GFP)-positive dots (D). Number of autophagic vesicle HeLa cells after various treatments $(E-G)$. Autophagic vesicles under electron microscopy in control HeLa cells $(E)$, in HeLa cells treated with $100 \mathrm{nM}(\mathbf{F})$, or with $0.2 \mu \mathrm{g} / \mathrm{mL}$ cisplatin $(\mathbf{G})$. Autophagic vesicles are indicated by arrows. ${ }^{* \star *} \mathrm{P}<0.001$.

To further confirm autophagy induction by cisplatin in HeLa cells, we observed autophagosome formation via electron microscopy. As shown in Figure 1E-G, compared to the control HeLa cells (Figure 1E), in which autophagic vacuoles were rarely seen, there were numerous membrane vacuoles in the rapamycin-treated (Figure 1F) or the cisplatin-treated HeLa cells (Figure 1G).

Aside from the formation of AVOs, a high conversion of microtubule-associated protein 1A/1B-light chain 3 (LC3) -I to LC3-II also occurs in autophagy, both of which play important role in autophagosome formation (Daido et al., 2004). To reconfirm autophagy induction by cisplatin, we then investigated the conversion of LC-I to LC-II via western blotting. As shown in Figure 2A and 2B, there was significant higher level of LC3-II compared to LC3-I in HeLa cells treated with rapamycin or cisplatin $(\mathrm{P}<0.001)$. In addition, as demonstrated in Figure $2 \mathrm{~A}$ and $2 \mathrm{C}$, the level of the autophagy-related protein 7 (Atg-7) was also significantly upregulated by rapamycin and cisplatin in HeLa cells. Taken together, our results confirmed autophagy induction by cisplatin treatment in cervical cancer HeLa cells. 
A

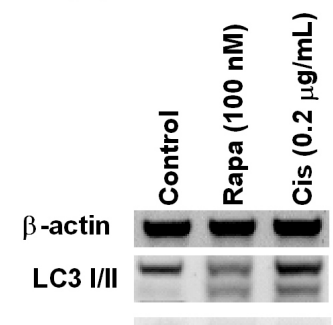

Atg-7
B

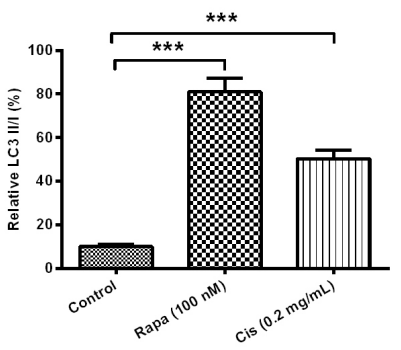

C

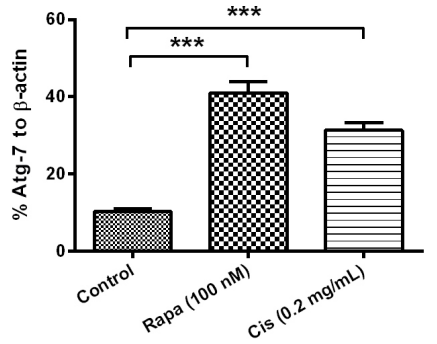

Figure 2. Cisplatin promotes autophagy-associated molecules in HeLa cells. A.-C. Western blot analysis of the conversion of LC3-I to LC3-II, and the autophagy-associated gene 7 (Atg-7) in control HeLa cells, and in HeLa cells treated with $100 \mathrm{nM}$ or $0.2 \mu \mathrm{g} / \mathrm{mL}$ cisplatin. Statistical significance are shown as ${ }^{* *} \mathrm{P}<0.001$. Results are obtained from three independently performed experiments.

\section{MA reduces autophagy induction by cisplatin and sensitizes HeLa cells to cisplatin}

To further determine the involvement of autophagy in the chemo-sensitivity of cervical cancer cells, we investigated induction of autophagy by cisplatin in HeLa cells with a chemical autophagy inhibitor, 3MA. As indicated in Figure 3A, formation of AVOs was significantly promoted in HeLa cells with singular cisplatin $(0.2 \mu \mathrm{g} / \mathrm{mL})$ treatment, whereas such promotion was reduced by $3 \mathrm{MA}$ treatment $(P$ $<0.01$; Figure 3A). Furthermore, the conversion of LC-I to LC-II as well as the level of Atg-7 were also significantly reduced by $3 \mathrm{MA}$ treatment $(P<0.05$; $P<0.01$; Figure $3 B-D)$. Therefore, the autophagy inhibitor 3MA effectively reduced cisplatin-induced autophagy in cervical cancer HeLa cells.

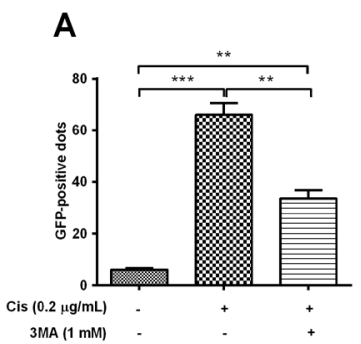

C

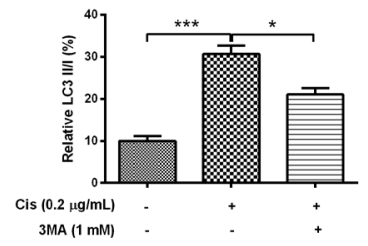

B

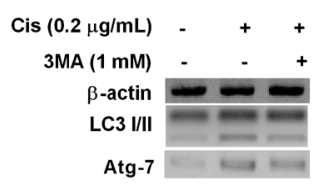

D

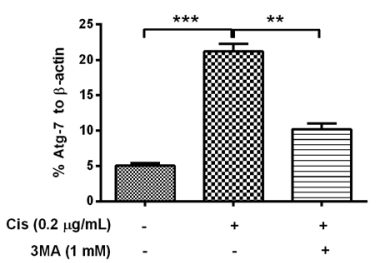

Figure 3. 3MA inhibits cisplatin-mediated promotion of autophagy-associated molecules in HeLa cells. A. 3MA reduced the formation of autophagic vesicles in HeLa cells treated with $0.2 \mu \mathrm{g} / \mathrm{mL}$ cisplatin; B. western blot analysis of LC3-I to LC3-II conversion and Atg-7 expression in HeLa cells treated with $0.2 \mu \mathrm{g} / \mathrm{mL}$ cisplatin or (and) $1 \mathrm{mM} 3 \mathrm{MA}$; C. relative levels of LC3-II to LC3-I in each group; D. percent levels of Atg-7 to $\beta$-actin in each group. All experiments were independently performed at least three times $\left({ }^{*} P<0.05\right.$, ${ }^{* *} P<0.01$ and $\left.{ }^{* * *} P<0.001\right)$. 
To determine the influence of the inhibition of autophagy by 3MA on the sensitivity of HeLa cells to cisplatin, we examined cell viability post-treatments with $3 \mathrm{MA}$, cisplatin, or both agents. Figure 4A demonstrated that cisplatin treatment significantly reduced the viability of HeLa cells, compared to the 3MA ( $P<0.01$ at 24 or $48 \mathrm{~h}$ post-treatment), as shown by the MTT assay. Moreover, the combined treatment significantly reduced viability of HeLa cells, as compared to singular treatments $(P<0.001$ at 24 or $48 \mathrm{~h}$ post-treatment). In addition, the combined treatment with both cisplatin and 3MA significantly upregulated apoptosis in HeLa cells, as compared to with 3MA or cisplatin alone ( $\mathrm{P}<0.05$ at 24 or $48 \mathrm{~h}$ post treatment). These results reveals that blocked autophagy by $3 \mathrm{MA}$ sensitizes cervical cancer cells to cisplatin treatments.

A

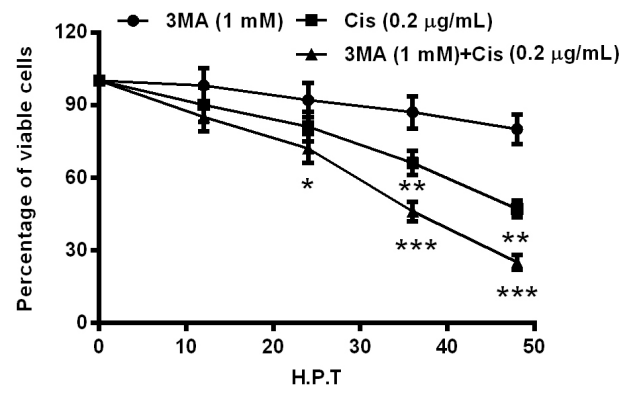

B

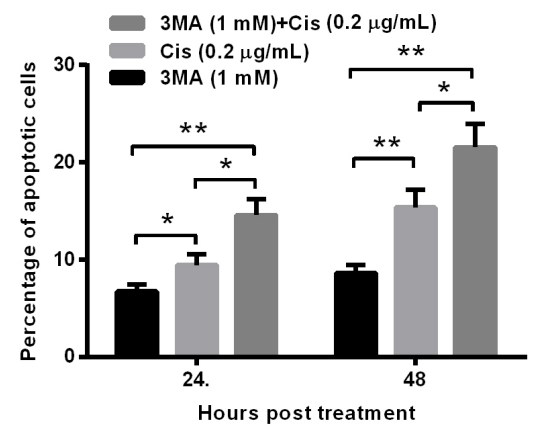

Figure 4. 3MA reduces cisplatin-mediated cell viability reduction and apoptosis induction in HeLa cells. A. Viability of HeLa cells post-treatment with $0.2 \mu \mathrm{g} / \mathrm{mL}$ cisplatin or (and) with $1 \mathrm{mM} \mathrm{3MA}$ for 12, 24, 36 or $48 \mathrm{~h}$; B. apoptosis induction by $0.2 \mu \mathrm{g} / \mathrm{mL}$ cisplatin or (and) with $1 \mathrm{mM} 3 \mathrm{MA}$ for 24 or $48 \mathrm{~h}$. Each result was averaged from three independent experiments. ${ }^{*} \mathrm{P}<0.05,{ }^{* *} \mathrm{P}<0.01$ or ${ }^{* * *} \mathrm{P}<0.001$.

\section{DISCUSSION}

Chemoresistance has been shown to be the main obstacle for radical treatments of cervical cancer and other types of malignances (Benedetto et al., 2015). Accumulating studies have indicated that autophagy plays an important role in the chemo-resistance of cancers (MartinezOutschoorn et al., 2011; Nencioni et al., 2013; Chang et al., 2014). In the present study, we recognized autophagy induction by the cisplatin treatment in cervical cancer HeLa cells. Treatment with $0.2 \mu \mathrm{g} / \mathrm{mL}$ cisplatin significantly promoted accumulation of autophagy-specific vesicles, i.e. acidic vesicular organelles (AVOs) (Paglin et al., 2001) in HeLa cell cytosol, which were confirmed by GFP-LC3 labeled autophagosomes and morphologic observation of autophagic vesicles. Additionally, protein expression of ATG7, LC3-I, and LC3-II were also examined, all of which play important roles in autophagosome formation (Daido et al., 2004). We further confirmed that the autophagy inhibitor, 3MA, could inhibit cisplatin-induced autophagy in the HeLa cells. Our results showed reduced AVO formation, reduced conversion of LC3-I to LC3-II, and of reduced ATG7 expression in the HeLa cells subject to both 3MA and cisplatin.

Moreover, we confirmed that autophagy inhibition by 3MA sensitized cervical cancer cells to cisplatin. According to MTT assay results, viability of HeLa cells post-treatment with both 3MA and cisplatin was significantly reduced as compared to cells treated with only 3MA or cisplatin. Such significant difference between the combined treatment and the singular treatment with either 
3MA or cisplatin was also confirmed in apoptosis induction of HeLa cells. Thus, we confirmed that blocked autophagy by 3MA sensitizes cervical cancer cells to cisplatin treatment.

In summary, the present study recognized autophagy induction by cisplatin in cervical cancer HeLa cells. Such autophagy induction might be an adaptive response of cervical cancer cells to chemotherapy. In addition, autophagy blockage sensitizes cervical cancer cells to the chemotherapy.

\title{
Conflicts of interest
}

The authors declare no conflict of interest.

\section{ACKNOWLEDGMENT}

\author{
Research supported by grant from the Guangdong General Hospital (Guangdong \\ Academy of Medical Sciences).
}

\section{REFERENCES}

Benedetto C, Salvagno F, Canuto EM and Gennarelli G (2015). Obesity and female malignancies. Best Pract. Res. Clin. Obstet. Gynaecol. 29: 528-540.

Burger H, Loos WJ, Eechoute K, Verweij, J et al. (2011). Drug transporters of platinum-based anticancer agents and their clinical significance. Drug Resist. Updates 14: 22-34.

Chang Z, Huo L, Li K, Wu Y, et al. (2014). Blocked autophagy by miR-101 enhances osteosarcoma cell chemosensitivity in vitro. Sci. World J. 2014: 794756.

Chen S and Guan JL (2013). Tumor-promoting and -suppressive roles of autophagy in the same mouse model of BrafV600Edriven lung cancer. Cancer Discovery 3: 1225-1227.

Chen S, Jiang YZ, Huang L, Zhou RJ, et al. (2013). The residual tumor autophagy marker LC3B serves as a prognostic marker in local advanced breast cancer after neoadjuvant chemotherapy. Clin. Cancer Res. 19: 6853-6862.

Daido S, Kanzawa T, Yamamoto A, Takeuchi H, et al. (2004). Pivotal role of the cell death factor BNIP3 in ceramide-induced autophagic cell death in malignant glioma cells. Cancer Res. 64: 4286-4293.

Ferlay J, Soerjomataram I, Dikshit R, Eser S, et al. (2015). Cancer incidence and mortality worldwide: sources, methods and major patterns in GLOBOCAN 2012. Int. J. Cancer 136: E359-386.

Gibbings D, Mostowy S, Jay F, Schwab Y, et al. (2012). Selective autophagy degrades DICER and AGO2 and regulates miRNA activity. Nat. Cell Biol. 14: 1314-1321.

Gozuacik D and Kimchi A (2004). Autophagy as a cell death and tumor suppressor mechanism. Oncogene 23: 2891-2906.

Jaeger PA and Wyss-Coray T (2009). All-you-can-eat: autophagy in neurodegeneration and neuroprotection. Mol Neurodegener. 4: 16.

Jemal A, Bray F, Center MM, Ferlay J, et al. (2011). Global cancer statistics. Ca- Cancer J. Clin. 61: 69-90.

Korkaya $\mathrm{H}$ and Wicha MS (2011). Inflammation and autophagy conspire to promote tumor growth. Cell Cycle 10: 2623-2624.

Lanciano R, Calkins A, Bundy BN, Parham G, et al. (2005). Randomized comparison of weekly cisplatin or protracted venous infusion of fluorouracil in combination with pelvic radiation in advanced cervix cancer: a gynecologic oncology group study. J. Clin. Oncol. 23: 8289-8295.

Lukka H, Hirte H, Fyles A, Thomas G, et al. (2002). Concurrent cisplatin-based chemotherapy plus radiotherapy for cervical cancer-a meta-analysis. Clin. Oncol. 14: 203-212.

Martinez-Outschoorn UE, Lin Z, Ko YH and Goldberg AF, et al. (2011). Understanding the metabolic basis of drug resistance: therapeutic induction of the Warburg effect kills cancer cells. Cell Cycle 10: 2521-2528.

Mathew R, Karantza-Wadsworth V and White E (2007). Role of autophagy in cancer. Nat. Rev. Cancer 7: 961-967.

Meta-Analysis Group, Medical Research Council Clinical Trials Unit, (2008). Reducing uncertainties about the effects of chemoradiotherapy for cervical cancer: a systematic review and meta-analysis of individual patient data from 18 randomized trials. J. Clin. Oncol. 26: 5802-12

Mizushima N, Levine B, Cuervo AM and Klionsky DJ (2008). Autophagy fights disease through cellular self-digestion. Nature 451: 1069-1075.

Nencioni A, Cea M, Montecucco F, Longo VD, et al. (2013). Autophagy in blood cancers: biological role and therapeutic implications. Haematologica 98: 1335-1343. 
Paglin S, Hollister T, Delohery T, Hackett N, et al. (2001). A novel response of cancer cells to radiation involves autophagy and formation of acidic vesicles. Cancer Res. 61: 439-44.

Pearcey R, Miao Q, Kong W, Zhang-Salomons J, et al. (2007). Impact of adoption of chemoradiotherapy on the outcome of cervical cancer in Ontario: results of a population-based cohort study. J. Clin. Oncol. 25: 2383-2388.

Vale C, Tierney JF, Stewart LA, Brady M, et al. (2008). Reducing uncertainties about the effects of chemoradiotherapy for cervical cancer: a systematic review and meta-analysis of individual patient data from 18 randomized trials. J. Clin. Oncol. 26: $5802-12$.

Verleye L, Vergote I, Reed N and Ottevanger PB (2009). Quality assurance for radical hysterectomy for cervical cancer: the view of the European Organization for Research and Treatment of Cancer-Gynecological Cancer Group (EORTC-GCG). Ann. Oncol. 20: 1631-1638.

White E and DiPaola RS (2009). The double-edged sword of autophagy modulation in cancer. Clin. Cancer Res. 15: 5308-5316. 